\title{
$\mathrm{X}$ \\ COLLECTANEA
}

DR. H. C. G. Semon states that an error has occurred in the account of the part which he took in the discussion on "The Toxic Effects of Arsenobenzol Treatment and their Prevention," as printed in our July issue. He is there quoted as having said "he had had one case of dermatitis, but never one of jaundice."

Dr. Semon, in the course of his statement, did not say that he had never had a case of jaundice, for, as our readers will see, he proceeded to speak of his experience with thiosulphate of soda in the treatment of jaundice.

We offer our apologies to Dr. Semon for the obvious contradiction which occurred in our report.

\section{NOTES ON MALARIA AND GENERAL PARALYSIS OF THE INSANE}

\author{
By JOHN W. TOMB, M.D., D.P.H., Asınsol, India.
}

No European medical man residing in the tropics can fail to be struck with the remarkable rarity of general paralysis of the insane amongst tropical races.

This striking condition of affairs may conceivably be due to four causes :-

(I) Rarity of infection with S. pallida.

(2) Infection by a "tropical," modified, or nonneurophile strain of that organism.

(3) A natural immunity to involvement of the central nervous system by $S$. pallida, or its toxin.

(4) An acquired immunity to the involvement of the central nervous system by $S$. pallida, or its toxin.

Of these four possible causes I suggest that the last is the principal one, and that the freedom of tropical races from general paralysis of the insane is due to their almost constant infection with malaria, and to the acquired immunity against general paralysis which this chronic infection affords. This hypothesis is naturally suggested 


\section{BRITISH JOURNAL OF VENEREAL DISEASES}

by the now well-attested and successful treatment of general paralysis by artificially-induced malarial fever, the favourable results of which cannot be attributed to the effects of fever alone, since the fever produced by malaria has been found greatly to exceed in value that produced by other agencies, such as $S$. recurrentis, or by $B$. Typhosus, Pneumococcus, etc., and would seem to be undoubtedly specific in character.

The antagonism between malaria and syphilis may also be a factor in the singular readiness with which artificiallyinduced malaria responds to the action of quinine in the paretic.

I venture to suggest that in all countries in which malaria is endemic an inverse ratio will in all probability be found to obtain between the incidence of general paralysis of the insane and chronic malarial infection, and that the asylums of such countries as Italy, Macedonia, and Palestine will show a definitely smaller proportion of cases of general paralysis amongst the inhabitants of the endemically malarious than of the non-malarious parts of those countries. In this connection it is highly significant that in the only portion of the tropical world where malaria is non-existent, i.e., in the Barbadoes Islands, general paralysis of the insane is, I am assured on the testimony of a European specialist in venereal diseases well acquainted with those islands, extremely common. 